\title{
SCIDiC
}

\author{
International Journal of Dentistry and Oral Science (IJDOS) \\ ISSN: 2377-8075
}

\section{Patient Satisfactory Levels Regarding The Dental Treatments In Private Dental Clinic}

Research Article

Dhanraj Ganapathy ${ }^{1 *}$, Miloni Suresh Shah ${ }^{2}$

'Professor and Head Department of Prosthodontics Saveetha Dental College Saveetha Institute of Medical and Technical Sciences Chennai, India.

${ }^{2}$ Graduate Student Saveetha Dental College, Saveetha Institute of Medical and Technical Sciences Chennai, India.

\section{Abstract}

Introduction: The purpose of this study is to evaluate the patient satisfactory levels regarding the dental treatments provided in a private dental clinic. Quality is a noteworthy worry of medicinal services organisations everywhere through out the world. Patients' fulfilment has been examined in numerous schools of dentistry in different nations. Dental objections made by patients may cause a lot of uneasiness and worry among dental care practitioners. It is critical for the calling to advance exclusive expectations of expert lead among dental specialists.

Materials and Methods: A cross sectional examination was led among people all over Chennai. The examination was directed in the long stretch of December, 2017. This investigation included a sample of 100 patients. They were requested to fill an online study comprising of 12 questions with respect to learning, mentality, awareness and their experience about undergoing a treatment in a private dental clinic. The outcomes were additionally assessed.

Results: It was seen that the greater part of talked with patients were happy with the patient- dental practitioner area, $(80 \%)$ dental practitioner communication, friendly nature, specialised competency, pain limitation, advices given after a treatment, authoritative effectiveness and centre set up condition at a private dental clinic.

Conclusion: From the above study it is seen that majority of the patients were satisfied with the treatment provided in a private dental clinic. The dominant part of patients were happy with the patient- dental practitioner communication, friendly nature, specialised competency, pain limitation, advices given after a treatment, authoritative effectiveness and centre set up condition at a private dental clinic.

Keywords: Satisfaction; Pain Management; Private Dental Clinic; Friendliness; Experience.

\section{Introduction}

The purpose of this study is to evaluate the patient satisfactory levels regarding the dental treatments provided in a private dental clinic.

Quality is a note worthy worry of medicinal services organisations every where throughout the world. Patients' fulfilment has been examined in numerous schools of dentistry in different nations. Dental objections made by patients may cause a lot of uneasiness and worry among dental care practitioners. It is critical for the calling to advance exclusive expectations of expert lead among dental specialists [1,2].

It is logical that levels of satisfaction may differ depending on which dental procedures are performed, as well as which clinical populations are being served. Criticism on fulfilment with respect to dental nurture consistent change of the administration conveyance process and outcome. Dental objections made by patients may cause a lot of nervousness and worry among dental care providers [3]. Dissatisfaction and dissensions may bring about patients changing their dental specialist, which may have repercussions as far as the family and companions' view of the dental practice. The point of this investigation is to decide patients'

*Corresponding Author:

Dhanraj Ganapathy,

Professor and Head Department of Prosthodontics Saveetha Dental College Saveetha Institute of Medical and Technical Sciences 162, Poonamalle High Road Chennai - 600077 Tamil Nadu, India.

Tel: 9841504523

Email Id: dhanrajmganapathy@yahoo.co.in

Received: April 12, 2021

Accepted: May 08, 2021

Published: May 18, 2021

Citation: Dhanraj Ganapathy, Miloni Suresh Shah. Patient Satisfactory Levels Regarding The Dental Treatments In Private Dental Clinic. Int J Dentistry Oral Sci. 2021;08(05):24832487. doi: http://dx.doi.org/10.19070/2377-8075-21000488

Copyright: Dhanraj Ganapathy ${ }^{\odot} 2021$. This is an open-access article distributed under the terms of the Creative Commons Attribution License, which permits unrestricted use, distribution and reproduction in any medium, provided the original author and source are credited. 
fulfilment with respect to the nature of dental care provided at a private dental clinic [4].

Patients' fulfilment with the dental care they get is significant in light of the fact that it will impact their example for benefit usage. It has been demonstrated that patients who were more happy with dental care would be wise to consistence, less un-went to arrangements, less uneasiness, torment and discernment. Dentist- understanding cooperations amid dental treatment have been shown to influence patients' consistence with clinical counsel and sense of duty regarding booked visits. In this way, data on patients' input and fulfilment is important to appropriately assess the administration being given [5].

There has been a significant growth in alternative types of dental practice. Patients evaluated the clinic minimum positively for all the components. Many studies have shown patient satisfaction in private dental clinics, a setting for which generalisability to other practice settings may be questionable [6].

It is vital for the calling to advance exclusive requirements of expert direct among dentists. In a time of clinical administration and patient organisation in conveying fantastic oral medicinal services, it is vital that patients' worries are managed appropriately [7].

This study aimed to determine the levels of satisfaction regarding the quality of dental care among patients at the dental clinics. However, what patients want from the services may differ from what the provider thinks is best for them. Therefore, their opinion should be incorporated to provide a holistic view in enhancing the understanding of the factors affecting patients' satisfaction with the health care setting. These include disciplines such as patient-personnel interaction, technical competency, system/ administrative efficiency and clinic setup/environment. Hence, this study attempts to quantify the level of satisfaction with the dental services specifically with reference to these disciplines of interest [10].

\section{Materials and Methods}

A cross sectional descriptive study, using convenience sampling method was conducted among people in Chennai. The examination was directed in the long stretch of December, 2017. This investigation included a sample of 100 patients. They were requested to fill an online study comprising of 12 questions with respect to mentality, awareness and their experience about undergoing a treatment in a private dental clinic. The questionnaire was prepared encompassing the dental practitioner communication, friendly nature of the dentist, specialised competency, pain limitation, advices given after a treatment, authoritative effectiveness and centre set up condition at a private dental clinic. The statistical analysis of the gathered data was carried out.

Questions consist of multiple choices and multiple sections with options for write in answers for appropriate. This study employed a self administered questionnaire that required less than 5 min to be completed and which has been shown to be an efficient and effective tool for collecting information.

The survey was closed after 2 weeks. The survey was then closed and the data was analysed by computing the percentage response for each question. Therefore the purposes of this study were to develop a measure of patient satisfaction with a dental visit; iden-

Figure 1. Questionnaire.

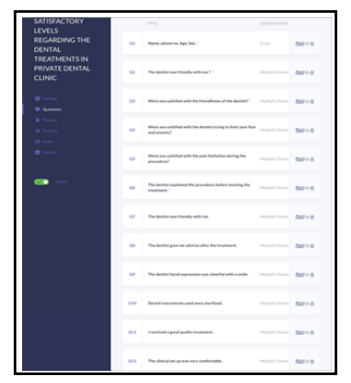

Figure 2. Depicts about the friendliness of the dentist.

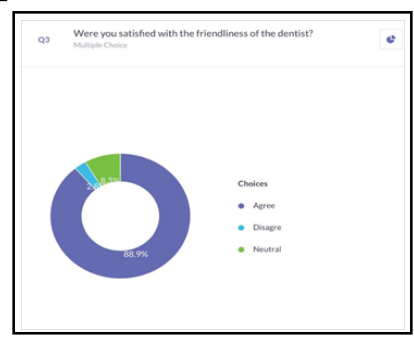

Figure 3. depicts about the satisfaction.

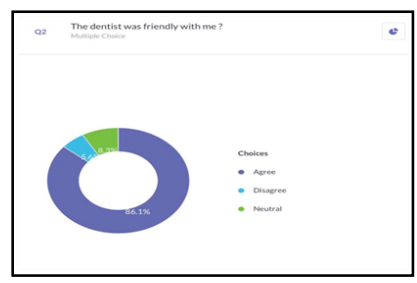


tify components of patient satisfaction; and test the hypothesis that certain dentist, patient, and procedural factors are associated with patient satisfaction. The data were collected and represented as graphs (Fig 1-12).

\section{Results}

\section{Discussion}

This examination analysed fulfilment evaluations of patients who had gotten treatment in a private dental centre. The measure of patient fulfilment was created particularly all together with the goal that the practitioners can have a thought regarding rolling out he required improvements. The extensive example permitted the utilisation of complex factual methodology to test for various parts inside the patient fulfilment information. The segments distinguished were an arrangement of relational relationship-comfort properties, clinical set up, materiel decision esteem factors, and tangible evaluative highlights, and each mirrors a perplexing arrangement of goal and subjective components. In general, the patient's fulfilment levels were high, and our evaluations are like those announced by another examination utilising comparative reaction decisions [11].

Patient satisfaction was estimated as follows : patient- dental spe-

Figure 4. depicts about the limitation of fear and anxiety.

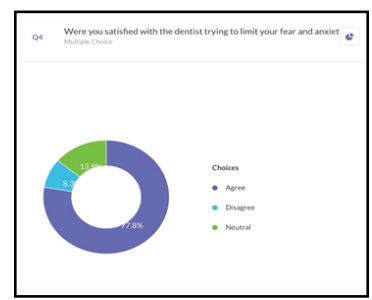

Figure 5. Satisfaction of pain limitation during the procedure.

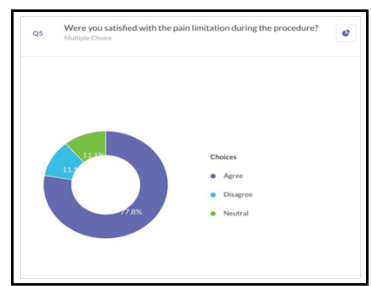

Figure 6. depicts about the dentist explaining about the procedure prior to the treatment.

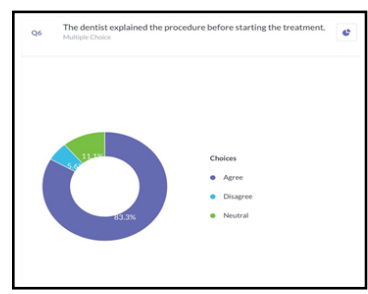

Figure 7. Depicts about the dentist patient relationship.

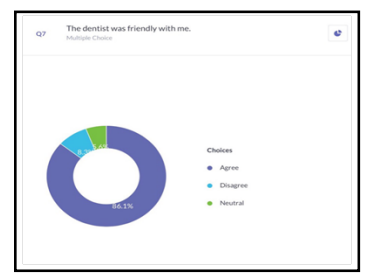

Figure 8. depicts about the advices given after the treatment. 
cialist connection (Fig. 2), specialised, regulatory and facility setup (Fig.12). It was seen that the greater part of talked with patients were happy with the patient- dental practitioner area, (80\%) and $(83.3 \%)$ of talked with patients conceded to the things about suppliers fixation amid their work and benevolent state of mind [12, 13].

The average percent mean score for satisfaction (19 items) as shown by Fig.11 shows a mean percentage of $(88.9 \pm 10.93 \%)$, although this is considered high, it was still lower than that reported by Bedi et. al (89\%) 6 but better than the satisfaction response reported by Othamn and Abdel-razal (61.7\%). ${ }^{2}$ Generally, this finding was similar to those reported by the British Dental Association independent polls, ${ }^{19}$ which showed that as many as 9 out of 10 people have confidence in the treatment they receive. A study conducted by Othman and Jaafar ${ }^{1}$ showed similar findings. However the overall results on satisfaction do not tell us about the weaknesses of the service or the problem encountered. Only further probing on the specific aspect of care will reveal areas of expressed dissatisfaction [14].

Dental practitioners clarified the methods previously the treatment (Fig. 6), which is a critical viewpoint in the patient- dental specialist fulfilment space spoke to with $78 \%$ of fulfilment among the considered example, which is in opposition to what was found by Othman and Abdel Razak (45.6\%)2, and this could be because of actualising this investigation in an instructive setting, which put high needs on teaching the understudies on and about the perfect method for correspondence and patient- dental practitioner collaboration. Rankin and Haris revealed that patients loathe having a dental specialist who starts treatment with no explanation [15, 16].

The inquiry identified with "Happy with holding up region" additionally demonstrated a critical factual contrast amongst Saudi and Non Saudi nationals. This might be credited to the higher desires of the Saudi nationals with respect to the administrations offered by a facility managed by a College of Dentistry, which is a scholarly organisation offering a specific dental care benefit.

In spite of the fact that there was a critical factual distinction amongst Saudis and Non Saudis in regards to security of the offered treatment, both indicated high fulfilment levels (90\%), low level of un-fulfilment that might be ascribed to outline of the centres.

A constraint of this examination was the avoidance of the female dental care due the way that the female centre is still under devel-

Figure 9. depicts about the facial expressions of the dentist.

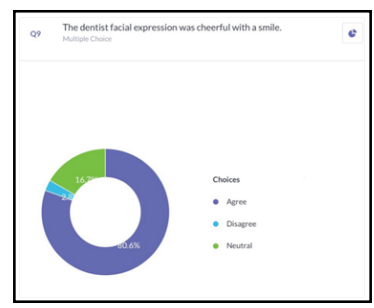

Figure 10. depicts about the sterilised instruments.

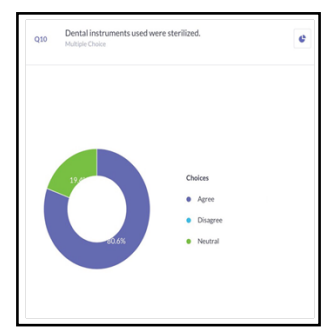

Figure 11. depicts about the quality of the treatment received.

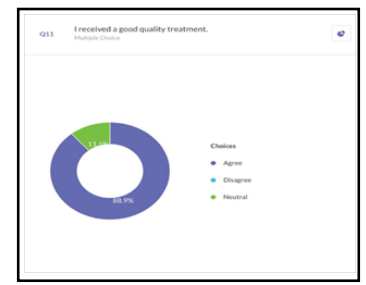

Figure 12. Depicts about the clinical set up.

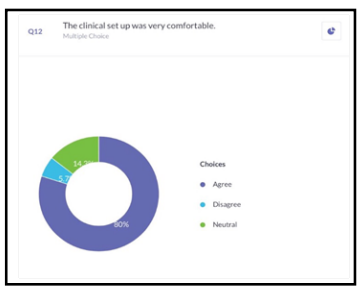


opment and has not yet gave any administrations.

This examination will go about as a guide for dental staff individuals on both male and female grounds to guarantee quiet fulfilment as a pointer for the nature of dental administrations, being a piece of the aggregate quality administration approach of the school and the college.

Dental practitioners clarified the methods previously the treatment, which is a critical viewpoint in the patient- dental specialist fulfilment space spoke to with $78 \%$ of fulfillment among the considered example, which is in opposition to what was found by Othman and Abdel Razak (45.6\%), and this could be because of actualising this investigation in an instructive setting, which put high needs on teaching the understudies on and about the perfect method for correspondence and patient- dental practitioner collaboration. Rankin and Haris revealed that patients loathe having a dental specialist who starts treatment with no explanation. This study will act as a guide for dental staff members to ensure patient satisfaction as an indicator for the quality of dental services [18, 19].

\section{Conclusion}

From the above study it is seen that majority of the patients were satisfied with the treatment provided in a private dental clinic. The dominant part of patients were happy with the patient- dental practitioner communication, friendly nature, specialised competency, pain limitation, advices given after a treatment, authoritative effectiveness and centre set up condition at a private dental clinic. These information recommend that a patient's judgments of dental practitioner's abilities and nature of care depend on individual collaborations with the dental practitioner, the level of solace, and post-treatment affect ability.

\section{References}

[1]. Gürdal P, Cankaya H, Onem E, Dinçer S, Yílmaz T. Factors of patient satisfaction/dissatisfaction in a dental faculty outpatient clinic in Turkey. Community Dent Oral Epidemiol. 2000 Dec;28(6):461-9. Pubmed PMID: 11106019.

[2]. Holt VP, McHugh K. Factors influencing patient loyalty to dentist and dental practice. Br Dent J. 1997 Nov 22;183(10):365-70. Pubmed PMID: 9419943.
[3]. Thomson WM, Stewart JF, Carter KD, Spencer AJ. Patient mobility in Australian dentistry. Community Dent Health. 1996 Jun;13(2):99-104. Pubmed PMID: 8763141.

[4]. Williams SJ, Calnan M. Convergence and divergence: assessing criteria of consumer satisfaction across general practice, dental and hospital care settings. SocSci Med. 1991;33(6):707-16. Pubmed PMID: 1957191.

[5]. Anderson R, Thomas DW, Phillips CJ. The effectiveness of out-of-hours dental services: II. patient satisfaction. Br Dent J. 2005 Feb 12;198(3):1516; discussion 146. Pubmed PMID: 15706385.

[6]. Othman L, Jaafar N. A survey of customer satisfaction with the school dental service among 16-year-old schoolchildren in the district of Tawau, Sabah [monograph]. Kuala Lumpur, Malaysia: Oral Health Division, Ministry of Health and University of Malaya. 2004.

[7]. Othman N, Razak IA. Satisfaction with school dental service provided by mobile dental squads. Asia Pac J Public Health. 2010 Oct;22(4):415-25. Pubmed PMID: 20462854.

[8]. Humphris GM, Cooper CL. New stressors for GDPs in the past ten years: a qualitative study. British dental journal. 1998 Oct;185(8):404-6.

[9]. O'Shea RM, Corah NL, Ayer WA. Why patients change dentists: practitioners' views. The Journal of the American Dental Association. 1986 Jun $1 ; 112(6): 851-4$

[10]. Bedi R, Gulati N, McGrath C. A study of satisfaction with dental services among adults in the United Kingdom. Br Dent J. 2005 Apr 9;198(7):433-7. Pubmed PMID: 15870803.

[11]. Mahrous MS, Hifnawy T. Patient satisfaction from dental services provided by the College of Dentistry, Taibah University, Saudi Arabia. Journal of Taibah University Medical Sciences. 2012 Dec 1;7(2):104-9.

[12]. Williams B, Coyle J, Healy D. The meaning of patient satisfaction: an explanation of high reported levels. SocSciMed. 1998 Nov;47(9):1351-9. Pubmed PMID: 9783878.

[13]. Calnan M, Dickinson M, Manley G. The quality of general dental care: public and users' perceptions. Qual Health Care. 1999 Sep;8(3):149-53. Pubmed PMID: 10847870.

[14]. Goedhart H, Eijkman MA, ter Horst G. Quality of dental care: the view of regular attenders. Community Dent Oral Epidemiol. 1996 Feb;24(1):2831. Pubmed PMID: 8833511.

[15]. Gopalakrishna P, Munnaleneni V. Influencing satisfaction for dental services. J Health Care Mark. 1993 Winter;13(1):16-22. Pubmed PMID: 10126026.

[16]. Burke L, Croucher R. Criteria of good dental practice generated by general dental practitioners and patients. Int Dent J. 1996 Feb;46(1):3-9. Pubmed PMID: 8744911.

[17]. Handelman SL, Jensen OE, Jensen P, Black PM. Patient satisfaction in a regular and after-hours dental clinic. Spec Care Dentist. 1996 SepOct;16(5):194-8. Pubmed PMID: 9582720.

[18]. Chu CH, Yeung CY, Lo EC. Monitoring patient satisfaction with university dental services under two fee-paying systems. Community Dent Oral Epidemiol. 2001 Oct;29(5):390-8. Pubmed PMID: 11553112.

[19]. Williams SJ, Calnan M. Convergence and divergence: assessing criteria of consumer satisfaction across general practice, dental and hospital care settings. SocSci Med. 1991;33(6):707-16. Pubmed PMID: 1957191.

[20]. Rankin JA, Harris MB. Patients' preferences for dentists' behaviors. Journal of the American Dental Association (1939). 1985 Mar 1;110(3):323-7. 